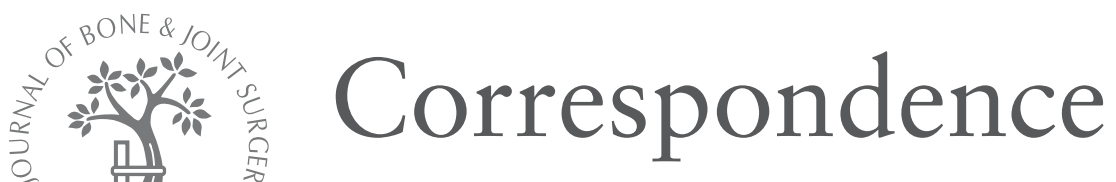

We welcome letters to the Editor concerning articles which have recently been published. Such letters will be subject to the usual stages of selection and editing; where appropriate the authors of the original article will be offered the opportunity to reply.

Letters should normally be under $\mathbf{3 0 0}$ words in length, doublespaced throughout, signed by all authors and fully referenced. The edited version will be returned for approval before publication.

(C)2006 British Editorial Society of Bone and Joint Surgery \$2.00 J Bone Joint Surg [Br] 2006;88-B:1545-6.

\section{The effect of the diameter of metal-on-metal bearings on systemic exposure to cobalt and chromium}

Sir,

We read the paper by Daniel et $\mathrm{al}^{1}$ in the April 2006 issue entitled 'The effect of the diameter of metal-on-metal bearings on systemic exposure to cobalt and chromium' with interest. Measuring and reporting metal ions after metal-on-metal hip replacement is a difficult task and we must acknowledge the science behind the method of measurement used by the authors (HR-ICPMS and validated measures). However, we have many concerns regarding their conclusion and their method of selecting patients.

Levels of metal ions may be influenced by many factors, which we can separate into subject-related, and tribological (related to the implant).

\section{Subject-related factors}

Four cohorts of patients have been selected without clear inclusion criterion. The measurement times following surgery were very different for the two sample mediums (two and five years for urine and one year for blood). The paper also lacked information to determine if groups were statistically comparable (gender, weight, height, body mass index, etc). Inclination of the acetabular component, a known factor affecting metal ion release is missing. ${ }^{2}$ Moreover, the selection of the $50 \mathrm{~mm}$ and 54 $\mathrm{mm}$ diameter surface replacement femoral components (with matching acetabular component sizes of $56 \mathrm{~mm}$ to $62 \mathrm{~mm}$ ) is larger than most average component sizes in total hip replacement (THR). Also, how many in each group were based on the diameter of the femoral component head and what was the mean component size? Lubrication of the articulation is improved for larger diameters during the early running-in phase and may bias surface replacement arthroplasty over THR.

\section{Tribological factors}

As stated in the paper, many factors affect metal-on-metal wear and metal ion production such as carbon content, clearance, sphericity and surface roughness. ${ }^{3}$ The Birmingham hip resurfacing (BHR) device and the Metasul $(28 \mathrm{~mm}$ diameter head) do not present the same characteristics. The BHR is cast, Metasul is forged, and the clearances, sphericity and surface roughness are different, hence the authors cannot conclude that component diameters do not influence wear. The authors should conclude that Metasul produces the same ion release characteristics as the $50 \mathrm{~mm}$ and $54 \mathrm{~mm}$ components. In order to investigate whether component diameter influences wear, the authors should have compared the metal ion level of their cohort of BHR hip replacement with a different component diameter, using metal-on-metal implants with the same tribological characteristics but with different component diameters.

By selecting larger than average component sizes in the surface replacement group, the authors may have selectively reduced the metal ion level of the group and compensated the tribological properties of the Metasul $28 \mathrm{~mm}$ implant favourably versus the BHR. We do not think that a retrospective cohort study, which introduces patient selection bias, comparing two implants with different tribological properties is appropriate to assess the scientific question raised by the authors.

doi:10.1302/0301-620X.88B11.18672

P. A. VENDITTOLI, MSc, FRCS, Assistant Professor of Surgery

M. LAVIGNE, MD, FRCS, Associate Clinical Professor

Hôpital Maisonneuve-Rosemont, Montréal, Canada.

1. Daniel J, Ziaee H, Salama A, Pradham C, McMinn DJW. The effect of the diameter of metal-on-metal bearings on systemic exposure to cobalt and chromium. J Bone Joint Surg [Br] 2006;88-B:443-8.

2. Brodner W, Grubl A, Jankovsky R, et al. Cup inclination and serum concentration of cobalt and chromium after metal-on-metal total hip arthroplasty. J Arthroplasty 2004;19(Suppl 3):66-70.

3. Rieker CB, Schon R, Konrad R, et al. Influence of the clearance on in-vitro tribology of large diameter metal-on-metal articulations pertaining to resurfacing hip implants. Orthop Clin North Am 2005:36:135-42.

\section{Author's reply:}

Sir,

We appreciate Drs Vendittoli and Lavigne's interest in our paper. In response to the concerns raised by them we would like to make the following comments.

\section{Patient-related factors}

Inclusion criteria were clearly stated in our paper and are as follows: well-functioning unilateral Metasul total hip replacements (THRs) or Birmingham hip replacements (BHRs) in patients with no other metal devices in the body, and who were at the appropriate time points planned for metal level measurement, were included. Diagnoses other than osteoarthritis, and patients who lived abroad or with impairment of renal function were excluded. The measurement times were spread over this extensive period in order to cover the largest possible duration, between one year and four to six years. Earlier studies predicted a run-in peak wear around one year and steady state wear in later years. The mean duration from operation was similar in the groups with the two different bearing sizes. 
There are bound to be minor variations in the acetabular inclination angles in any group of arthroplasty patients. Vendittoli and Lavigne quote the report by Brodner et $\mathrm{al}^{1}$ to highlight the effect of acetabular inclination angle on metal ion release. In that study no correlation could be found between inclination angles and cobalt or chromium levels and no significant differences were found between the median metal ion levels in groups of patients with the greatest, lowest and intermediate inclination angles. They found three outliers in terms of serum metal ions (with levels ranging up to $26.8 \mu \mathrm{g} / \mathrm{l}$ for cobalt and $33.6 \mu \mathrm{g} / \mathrm{l}$ for chromium) who had abnormally high inclination angles. In our study there were no outliers with abnormally high blood levels in either group. This observation rules out the suggestion that there may be individual metal ion variations as a result of steep inclination angles in one device group or the other.

In our own unpublished work we have data which shows that neither height, weight, body mass index, patient activity, nor a combination of these factors, nor inclination angle of the cup nor age show any association with output of metal ions in the urine or metal levels in blood.

\section{Implant-related factors}

Resurfacings are bound to be of a larger diameter than $28 \mathrm{~mm}$ hip replacements. The $28 \mathrm{~mm}$ bearing is the most frequently used in THR in our centre and is one of the most commonly used bearing diameters in THRs everywhere. The $50 \mathrm{~mm}$ and $54 \mathrm{~mm}$ bearings are the most frequently used BHR bearings. Therefore these sizes were chosen.

Differences in the actual diametral clearances are inevitable when bearings of different diameters are used, even if these bearings have been designed to provide the same geometric configuration. A bearing with a smaller diameter will always have a lower clearance. For instance, in the design of the Metasul bearing, Schmidt et $\mathrm{al}^{2}$ proposed a clearance of $200 \mu \mathrm{m}$ for bearings with a diameter of between $37 \mathrm{~mm}$ and $42 \mathrm{~mm}$ and appropriate smaller clearances for bearings with a diameter of $28 \mathrm{~mm}$. Campbell ${ }^{3}$ reported clearances in retrieved $28 \mathrm{~mm}$ Metasul bearings to be in the range of $100 \mu \mathrm{m}$ to $150 \mu \mathrm{m}$. The clearances of the $50 \mathrm{~mm}$ and $54 \mathrm{~mm}$ BHR bearings have comparable geometric configuration to the clearance of the 28 $\mathrm{mm}$ Metasul bearings. For surface roughness ${ }^{4}$ both the BHR and the Metasul fall in the same range and therefore this factor is unlikely to have affected the results.

Our study does not claim to compare the tribology of one system with another. Vendittoli and Lavigne conclude that the "larger than average component sizes in the surface replacement group might have selectively reduced the metal ion level of the group and compensated the tribological properties of the Metasul $28 \mathrm{~mm}$ implant favourably versus the BHR". In doing so they are assuming that the finding in the hip simulator that larger bearing diameters wear less, always works in an identical manner in vivo (i.e. bearings of a larger diameter generate less metal ions). However, in the only published report ${ }^{5}$ on the effect of the diameter of the bearing on metal ion levels, it was shown that bearings of a larger diameter generate more metal ions. This contradicts the simulator results. We conducted our study in order to verify or disprove the information in that report.

In order to overcome one very obvious problem in the earlier publication (i.e. metallurgic confounding factors) we chose to perform the study with systems that are both made of high carbon cobalt chrome alloy, while retaining similar bearing diameters as used in the earlier report. We highlighted in our paper that Metasul is of the forged variety and the BHR as-cast, however, no carbidedepleting late-stage heat treatments were performed on either device.
We fully agree that a systematic review of prospective double blinded randomised controlled trials (RCT) provides more robust evidence than a retrospective cohort study. However, the question of whether an RCT is the best study design in surgical and orthopaedic practice continues to be debated. ${ }^{6-8}$ We do not agree that a retrospective study has no place in scientific enquiry. A retrospective cross-sectional study gives a snapshot of the temporal trends in metal ion exposure and is particularly useful for guidance on study design and in sample size and power determination of a longitudinal study. Metal ion levels exhibit time-related changes following hip replacement. A cross-sectional study provides the basis to decide the critical time intervals when measurements of metal levels should be made in a prospective longitudinal trial. We appreciate that Lavigne and Vendittoli are involved in a longitudinal study and that the fiveto-six year results are unlikely to be available for another two to three years. We too are involved in such a study and are awaiting the medium-term results in that study before publication.

The preliminary work on metal ions by Lavigne et $\mathrm{al}^{9,10}$ has shown that in addition to cobalt and chromium, their resurfacing device (Durom) released elevated levels of titanium, evidently from the titanium plasma spray cementless fixation surface of the cup. Studies ${ }^{11,12}$ have shown that titanium alloy THRs produce up to a fivefold increase in chromosomal aneuploidy, compared with control subjects and cobalt-chrome THRs, which produce up to a 2.5fold increase in aneuploidy and a 3.5 -fold increase in chromosomal translocations. It is known that both titanium ${ }^{13}$ and the elements in cobalt-chrome $^{14}$ alloy also lead to hypersensitivity. The possible synergistic effects of elevated levels of the constituent elements of cobalt-chrome and titanium in the same patient are still unknown and are a matter of great concern. The BHR, with an integral porous surface, eliminates that element of possible adverse synergism between titanium and cobalt-chrome.

doi:10.1302/0301-620X.88B11.18673

J. DANIEL, FRCS, Director of Research

H. ZIAEE, BSc(Hons), Biomedical Scientist

C. PRADHAN, FRCS, Staff Orthopaedic Surgeon

D. J. W. McMINN, FRCS, Consultant Orthopaedic Surgeon

The McMinn Centre,

Birmingham, UK.

1. Brodner W, Greble A, Jankovsky R, et al. Cup inclination and serum concentration of cobalt and chromium after metal-on-metal total hip arthroplasty I Arthroplasty 2004;19(Suppl 3):66-70.

2. Schmidt M, Weber H, Schon R. Cobalt chromium molybdenum metal combination for modular hip prostheses. Clin Orthop 1996;329 (Suppl):35-47.

3. Campbell P, Shen FW, McKellop H. Biologic and tribologic considerations of alternative bearing surfaces. Clin Orthop 2004;418:98-111.

4. Pynsent WB, Band T. Smith and Nephew Product Reports. N162.002 and N165.001.

5. Clarke MT, Lee PTH, Arora A, Villar RN. Levels of metal ions after small and large diameter metal-on-metal hip arthroplasty. J Bone Joint Surg [Br] 2003;85-B:913-17.

6. McCulloch P, Taylor I, Sasako M, Lovett B, Griffin D. Randomised trials in surgery: problems and possible solutions. BMJ J2002;324:1448-51.

7. Hartling L, McAlister FA, Rowe BH, et al. Challenges in systematic reviews of therapeutic devices and procedures. Ann Intern Med 2005; 142:1100-11.

8. Amstutz HC. Innovations in design and technology: the story of hip arthroplasty. Clin Orthop 2000;378:23-30

9. Lavigne M, et al. Early results of a RCT comparing conventional and resurfacing total hip arthroplasty. International Symposium on Resurfacing of the hip joint Zurich, 2005.

10. Lavigne M, Vendittoli PA. Early results of a randomized controlled trial of hip resurfacing and total hip arthroplasty: OSTEOLOGIE-OSTEOLOGY. Interdisciplinary Journal for Bone and Joint Studies 2005; 14 (Suppl 2):80-3.

11. Doherty AT, Howell RT, Ellis LA, et al. Increased chromosome translocations and aneuploidy in peripheral blood lymphocytes of patients having revision arthroplasty of the hip. Jone Joint Surg [Br] 2001;83-B:1075-81.

12. Ladon D, Doherty A, Newson R, et al. Changes in metal levels and chromosome aberrations in the peripheral blood of patients after metal-on-metal hip arthroplasty. J Arthroplasty 2004;19(8 Suppl 3):78-83.

13. Lalor PA, Revell PA, Gray AB, et al. Sensitivity to titanium: a cause of implant failure? $J$ Bone Joint Surg [Br] 1991;73-B:25-8.

14. Willert HG, Buchhorn GH, Fayyazi A, et al. Metal-on-metal bearings and hypersensitivity in patients with artificial hip joints: a clinical and histomorphological study. J Bone Joint Surg [Am] 2005;87-A:28-36. 